\title{
Climate modes in southern high latitudes and their impacts on
} \section{Antarctic sea ice}

\author{
Xiaojun Yuan ${ }^{1}$ and Cuihua $\mathrm{Li}^{1}$ \\ Received 19 December 2006; revised 10 March 2008; accepted 1 April 2008; published 18 June 2008.
}

[1] This study investigates the influence of high-latitude climate variability on the Antarctic sea ice distribution. The climate variability examined here includes distinct climate modes, such as the Southern Annular Mode (SAM), quasi-stationary wave-3 pattern, Pacific South American pattern (PSA) and Semi-Annual Oscillation (SAO). The results reveal that the largest impact comes from PSA in the Antarctic Dipole (ADP) region of the western hemisphere at the interannual timescale, which is related to the teleconnection of El Niño-Southern Oscillation (ENSO). The wave-3 pattern also has a strong and similar influence on sea ice in the ADP regions as PSA does, suggesting a positive interaction between PSA and wave- 3 in the region. Measured by correlation coefficients and their significance, SAM has a relatively less significant influence on sea ice than other climate patterns in general, though this global assessment may not apply to particular regions. Sea ice usually responds to large-scale atmospheric anomalies with a 2-month delay. The singular value decomposition (SVD) analysis reveals that the coupled relationships between sea ice and atmospheric pressure, temperature, and wind fields are represented by these known climate modes. The leading coupled modes between sea ice and sea level pressure are accountable for $50 \%$ to $60 \%$ of total squared covariance for all seasons. The leading modes between sea ice and surface air temperature in winter and summer are also accountable for the same amount of total squared covariance. It indicates that these well-established climate modes/patterns are the dominant factors leading to a strong interaction between the atmosphere and sea ice field in the Antarctic.

Citation: Yuan, X., and C. Li (2008), Climate modes in southern high latitudes and their impacts on Antarctic sea ice, J. Geophys. Res., 113, C06S91, doi:10.1029/2006JC004067.

\section{Introduction}

[2] Numerous studies suggest a strong link between the tropical El Niño-Southern Oscillation (ENSO) phenomenon and Antarctic sea ice variability [Simmonds and Jacka, 1995; White and Peterson, 1996; Harangozo, 2000; Yuan and Martinson, 2000, 2001; Rind et al., 2001; Kwok and Comiso, 2002; Martinson and Iannuzzi, 2003]. The strongest tropical-polar teleconnections in temperature and sea ice fields are represented by the Antarctic Dipole mode (ADP) with anomalous centers in the northeastern Ross Gyre in the Pacific sector, and the central Weddell Gyre in the Atlantic sector of the Southern Ocean. The ADP temperature anomalies present the largest ENSO signal outside of the tropical Pacific [Liu et al., 2002]. It also represents the largest interannual variability in the Antarctic sea ice field. The changes of the basin-scale meridional circulation in the South Pacific and South Atlantic and stationary Rossby wave propagation associated with the

\footnotetext{
${ }^{1}$ Lamont-Doherty Earth Observatory of Columbia University, Palisades, New York, USA.

Copyright 2008 by the American Geophysical Union. 0148-0227/08/2006JC004067
}

ENSO variability are suggested as the main mechanisms for this tropical/polar teleconnection [Yuan, 2004]. However, besides the ENSO impact, a number of distinct high-latitude climate modes exist at intraseasonal to decadal timescales in the Southern Hemisphere. Those regional climate variabilities likely influence Antarctic sea ice but their impacts are less well understood. Particularly, the relative importance of the impact from different climate modes has not been addressed before. This study systematically investigates the influences of high-latitude climate variability on the Antarctic sea ice distribution.

[3] The high-latitude climate variability examined here includes the following distinct climate modes in southern mid to high latitudes. First, the Pacific South America (PSA) pattern, which dominates climate variability in the subpolar/polar regions of the South Pacific, is considered. The PSA pattern was suggested as part of the stationary Rossby wave train, which is usually generated by the changing of the tropical convection [Mo and Higgins, 1998]. Earlier studies [Karoly, 1989; Mo and Higgins, 1998; Kiladis and Mo, 1998; Garreaud and Battisti, 1999] have attributed the Rossby wave to the propagation of the ENSO signal to southern high latitudes. Therefore, at the interannual timescale, the PSA pattern is associated with 
Table 1. Major Climate Modes in Mid-High Latitudes of the Southern Hemisphere

\begin{tabular}{|c|c|c|c|c|}
\hline & $\begin{array}{l}\text { Pacific South } \\
\text { American } \\
\text { Pattern (PSA) } \\
\end{array}$ & $\begin{array}{c}\text { Stationary Wave-3 } \\
\text { Pattern (wave-3) }\end{array}$ & $\begin{array}{c}\text { Southern Annular } \\
\text { Mode (SAM) }\end{array}$ & $\begin{array}{c}\text { Semi-Annual } \\
\text { Oscillation (SAO) } \\
\end{array}$ \\
\hline $\begin{array}{l}\text { Surface fields that } \\
\text { modes present }\end{array}$ & SLP & sea ice, SLP, winds & SLP, winds & $\begin{array}{c}\text { Meridional gradients } \\
\text { of SAT and SLP }\end{array}$ \\
\hline Characteristics & $\begin{array}{l}\text { Three alternating pressure } \\
\text { anomaly centers in south } \\
\text { Pacific, southeast } \\
\text { Pacific polar seas and } \\
\text { South America }\end{array}$ & $\begin{array}{l}\text { Quasi-stationary waves } 3 \\
\text { around the global at } \\
\text { midlatitudes; strong in } \\
\text { winter; swinging east- } \\
\text { westward over an annual } \\
\text { cycle }\end{array}$ & $\begin{array}{l}\text { Annular shaped, } \\
\text { out-of-phase pressure } \\
\text { anomalies in polar } \\
\text { and midlatitude regions }\end{array}$ & $\begin{array}{l}\text { Enhanced meridional } \\
\text { temperature pressure } \\
\text { gradients (south of } 50^{\circ} \mathrm{S} \text { ) } \\
\text { in spring and autumn }\end{array}$ \\
\hline $\begin{array}{l}\text { Dynamical or } \\
\text { physical } \\
\text { causality }\end{array}$ & $\begin{array}{c}\text { Rossby wave train } \\
\text { [Karoly, 1989] }\end{array}$ & $\begin{array}{l}\text { Midlatitude land-ocean } \\
\text { distribution [van Loon } \\
\text { and Jenne, 1972] }\end{array}$ & $\begin{array}{l}\text { Eddies and mean flow } \\
\text { interaction [Lorenz and } \\
\text { Hartmann, 2001] }\end{array}$ & $\begin{array}{l}\text { Differential solar heating } \\
\text { at mid and high latitudes } \\
\text { [van Loon, 1967] }\end{array}$ \\
\hline
\end{tabular}

ENSO variability, creating persistent anomalous high- (low-) pressure centers in the Amundsen Sea in response to ENSO warm (cold) events, respectively. The anomalous pressure center consequently generates the out-of-phase sea ice/ temperature anomalies east of the Ross Sea and in the Weddell Gyre simultaneously through thermodynamic and dynamic processes [Kwok and Comiso, 2002; Renwick, 2002; Yuan, 2004].

[4] The second mode considered in this study is the quasi-stationary wave-3 pattern in the southern midlatitudes, a predominant winter mode in pressure/wind fields as initially discussed by van Loon [1972]. The land/ocean distribution in the midlatitudes of the Southern Hemisphere likely creates and maintains the wave- 3 pattern. Raphael [2004] described the spatial and temporal variability of the wave-3 pattern. Yuan et al. [1999] showed that three southerly branches of the wave-3 pattern coincide with three northward maximum extent of sea ice edge during late winter 1996, suggesting the role of the wave-3 pattern in advancing the ice edge at synoptic timescales. The wave3 pattern is also positively coupled with the ice edge distribution, promoting eastward propagation of the ice edge maxima and providing preferred locations for cyclonegenesis in the open ocean north of the ice cover. This case study suggested that the wave-3 pattern actively interacts with the sea ice field beneath. However, no thorough study has been done on the influence of wave- 3 on sea ice in other seasons and at different timescales.

[5] The third mode is the Southern Annular Mode (SAM) marked by a zonally symmetric but out-of-phase pressure anomalies between mid and high latitudes. It is a dominant climate mode in the Southern Hemisphere with maximum variability at 10-day period [Thompson and Wallace, 2000], and also explains $50 \%$ of the monthly SLP variance over Antarctica [Gong and Wang, 1999]. The mechanism that maintains this climate mode was suggested by a positive feedback between eddy activity in mid-high latitudes and zonal mean flow [Lorenz and Hartmann, 2001]. Hall and Visbeck [2002] in a modeling study showed that positive SAM means a stronger westerly, which creates a more northward ice transport resulting in thinner ice near the coast and thicker ice near the ice edge. Lefebvre et al. [2004] used a different model and concluded that the SAM index is modestly correlated with sea ice with marginal significance and ice concentration response to SAM is outof-phase in the Ross Sea and Weddell Sea instead of a zonally symmetric response. In addition, Liu et al. [2004] in a diagnostic study showed the out-of-phase response of sea ice in the ADP regions to the SAM variability. They also pointed out that the trend in the SAM index couldn't explain the total trend in Antarctic sea ice of the region.

[6] Last, the semi-annual oscillation (SAO), which describes another more or less zonally symmetric mode in the southern subpolar region, is considered. SAO is characterized by the twice-yearly enhancement in meridional gradients of temperature and pressure fields [van Loon, 1967, 1984; Simmonds and Jones, 1998; van den Broeke, 1998; Walland and Simmonds, 1999] due to differential cooling and heating on the Antarctic continent and in the midlatitude ocean [van Loon, 1967]. Associated with SAO, the atmospheric convergence line with a strong half-year cycle exerts significant influences on the temporal asymmetric behavior of ice extent: slowly advancing equatorward in fall and fast retreating in spring [Enomoto and Ohmura, 1990]. SAO also influences the open water areas within the sea ice pack [Watkins and Simmonds, 1999]. van den Broeke [2000a] suggested that the weakening of SAO since the late 1970 s and increased storminess during solstitial months have had a direct impact on the timing of sea ice advance and retreat. Stammerjohn et al. [2003] showed that the timing of the semi-annual migration of the Circumpolar Trough dynamically influences the timing of sea ice advance and retreat in the Western Antarctic Peninsula.

[7] All four climate modes mentioned above have clearly physical or dynamic reasons for their existence. Table 1 summarizes the characteristics of these climate modes, the atmospheric variables in which they appear, and the mechanisms that generate them. However, their relative importance in the southern hemisphere climate variability and their individual contribution to the influencing of Antarctic sea ice remains unknown. In this study, we comparatively examine the spatial and temporal characteristics of these climate modes and assess the relative importance of these modes in terms of influencing the sea ice variability around the Antarctic.

\section{Data}

[8] This study used satellite-observed sea ice concentrations (SIC) from 1978 to 2002, provided by the National Snow and Ice Data Center. These space-born passive microwave measurements of polar sea ice taken over more 
than 20 years provide observations of sea ice concentrations with a typical spatial resolution of $25 \mathrm{~km}$ and near daily temporal resolution, enabling us to study sea ice variabilities from synoptic to decadal timescales. The monthly sea ice concentration data used in this study are derived from observed brightness temperatures by the bootstrap algorithm [Comiso et al., 1997]. Although there are differences in ice concentrations produced by different algorithms [Comiso et al., 1997], those differences are rather small compared to the signal that we are examining here.

[9] To investigate relationships between Antarctic sea ice and mid- to high-latitude climate, several variables from the National Centers for Environmental Prediction (NCEP)National Center for Atmospheric Research (NCAR) reanalysis data [Kalnay et al., 1996; Kistler et al., 2001] were used, which include monthly surface air temperature (SAT) at $1000 \mathrm{mb}$, sea level pressure (SLP), $300 \mathrm{mb}$ and $500 \mathrm{mb}$ heights, vector winds at $10 \mathrm{~m}$ height, and meridional winds at $300 \mathrm{mb}$ surface. All of these variables except vector winds at $10 \mathrm{~m}$ are in class $\mathrm{A}$ of the reanalysis output, indicating that the variables are most strongly influenced by observation with minimal model impact. Vector winds at $10 \mathrm{~m}$ are classified into class $\mathrm{B}$, indicating that the variable is strongly influenced by the model even though observational data exist. Besides inadequate observations input into the reanalysis in the Southern Ocean, a few known problems and errors exist in the NCEP/NCAR reanalysis, as discussed by Kistler et al. [2001]. Among them, the PAOBs error has the most impact on the Southern Ocean assimilation. PAOBs are estimates of the SLP produced by the Australian Bureau of Meteorology. NCEP/NCAR reanalysis unfortunately shifted $180^{\circ}$ of longitude in the use of the data for 1979-1992. The problem is significant on a synoptic scale but becomes small in monthly mean fields [Kistler et al., 2001]. Examinations of the ENSO related variability from independent data sources suggest that the variability in NCEP/NCAR pressure/wind fields are consistent dynamically and thermodynamically with the variability in satellite observed sea ice and in situ SST data [Yuan, 2004]. Such consistency implies that the PAOBs error in NCRP/NCAR pressure fields has minimal impacts on the phenomena we study here. In addition, Hines et al. [2000] found that NCEP/NCAR SLP in southern high latitudes has an artificial long-term trend, though interannual variability is reasonably well captured after 1970s. To confirm that the PAOBs error has minimal impact on the climate patterns in this study, we calculated the PSA index from monthly data of NCEP/NCAR reanalysis and from monthly ERA40, where the error does not exist. The two indices compare extremely well, with a correlation of 0.97 for the period of 1970 onward. NCEP/NCAR reanalysis monthly mean data from 1950 to 2003 were used to examine the variability and characteristics of the climate modes in the Southern Ocean and the data from 1978 to 2003 were used to investigate the impacts of the climate modes on the sea ice field.

\section{Coupled Relationships Between Sea Ice and Atmosphere}

[10] To examine the relationship between sea ice and the atmosphere, the singular value decomposition (SVD) analysis is applied to satellite observed sea ice data and several atmospheric variables (300 mb height, $500 \mathrm{mb}$ height, sea level pressure, surface air temperature, surface vector winds, and vector winds at $300 \mathrm{mb}$ height) from NCEP/NCAR reanalysis. The pressure and wind fields represent dynamical structures of the atmosphere from the surface through the troposphere. Surface air temperature is related to the sea ice field thermodynamically. The SVD analysis is a powerful decomposition method to extract the co-variability between two climate fields [Bretherton et al., 1992]. The decomposition yields a series of spatially orthogonal modes that can be linearly combined to reconstruct the original covariance matrix. Each mode has a pair of spatial patterns (eigenvectors) that explain maximum mean squared temporal covariance between the two fields (units are the product of the units from the two fields) and a pair of synthetic time series (principle components). Here we construct seasonal time series for all variables by lining up 3 months in each season sequentially for all years. In space, sea ice is averaged into a $4^{\circ}$ longitude by $1^{\circ}$ latitude grid and atmospheric variables are averaged into a $5^{\circ} \times 5^{\circ}$ grid to speed up the calculation. That yields a total of 1139 ice grid points and 1080 atmosphere grid points. The SVD analysis is then conducted on the cross-covariance matrix from these seasonal time series.

[11] The analysis reveals that the sea ice field is mostly coupled with the atmosphere in the forms of the known climate patterns, particularly SAM, wave-3 pattern and PSA pattern. Figure 1 shows the spatial patterns of the leading SVD mode between winter sea level pressure and sea ice. The pressure field is characterized by out-of-phase pressure anomalies between the polar region and subpolar region (the character of SAM) and the PSA pattern in the South Pacific and South Atlantic. In addition, a wave- 3 pattern is visible in midlatitudes between $40^{\circ}$ and $50^{\circ} \mathrm{S}$. Covaried with this pressure pattern is the wave- 3 pattern with the dominant branch at the ADP region in the winter ice field. Figure 2 gives another example of the leading coupled mode between winter meridional wind and sea ice fields. The wave-3 pattern dominates both wind and ice fields with the strongest branch in the ADP region.

[12] In addition to the spatial patterns of the leading SVD modes, the percentages of the total squared covariance explained by the leading modes also reveals that the dominant sea ice and atmosphere interaction happens in the forms of these known climate modes. The leading coupled modes between ice and pressure fields (gh300, gh500 and SLP) are accountable for 50-60\% of total squared covariance for all seasons. The leading mode between ice and surface air temperature is also accounted for above $50 \%$ of total squared covariance in winter and summer. The second SVD modes between ice and pressure fields can only explain less than half of the squared covariance that the leading modes do for all seasons. In the case of ice and surface air temperature, the second SVD mode only explains less than a third of squared covariance that the leading mode explained in winter and summer. The significant drops in the percentages of the total squared covariance explained by the second SVD modes imply that any other patterns or possible traveling components introduced by adding higher modes are likely secondary phenomena.

[13] A number of outputs in the SVD analysis provide different descriptions of the relationships between the 

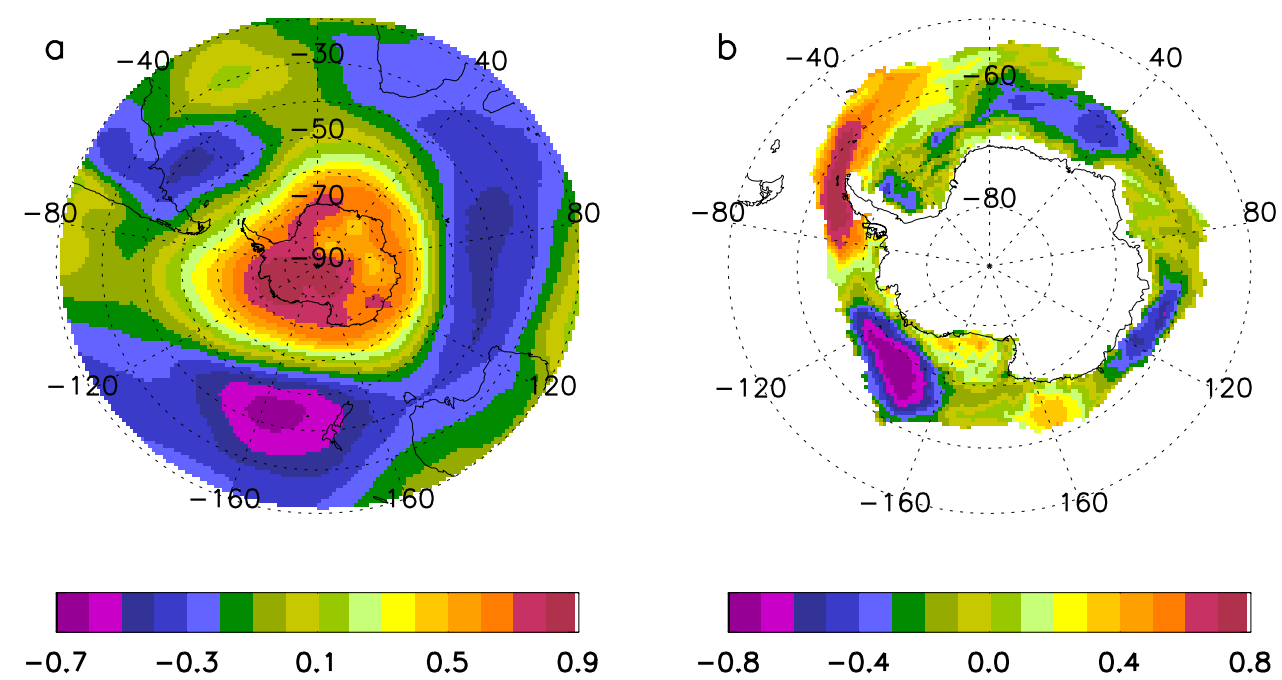

Figure 1. Spatial patterns of the leading SVD mode between (a) winter (June, July and August) SLP anomaly from $20^{\circ}$ to $90^{\circ} \mathrm{S}$ and (b) winter (JJA) sea ice concentration anomaly. This leading mode describes $57 \%$ of total squared covariance between these two fields.

atmosphere and sea ice field. One of these gives the percentage of the total variance in the ice field explained statistically by the leading mode of each atmospheric variable. Figure $3 \mathrm{a}$ shows this variance as a function of atmospheric variables and function of seasons. Although the variability among different atmospheric variables is quite small, seasonal variation is obvious, ranging from $7 \%$ in summer to about $20 \%$ in winter. Apparently, the atmosphere exerts more influence on sea ice field in winter than in any other season. Figure $3 \mathrm{~b}$ displays another output that gives the percentage of the total variance of each atmospheric variable explained statistically by the first mode of the ice field. In contrast to the parameter in Figure 3a, this second parameter varies largely among different atmospheric variables, ranging from $7 \%$ in wind fields to above $40 \%$ in pressure fields. It suggests that the sea ice distribution likely affects the overlying atmospheric pressure field more easily than affects temperature and wind fields. In general, the leading mode of sea ice is associated with more variance in the atmosphere during summer than winter, contrasting to the reversed processes shown in Figure 3a. In addition, sea ice has a particularly stronger influence on summer surface air temperature than any other season. Summer is the season when the ice coverage changes greatly: from zero percent to some significant coverage depending on the region. This result reflects the importance of the ice cover in determining air temperature. Regardless of seasons, sea ice fields share much less variance with wind fields than they do with the pressure and summer temperature fields.

[14] Comparing Figures 3a and 3b, the leading mode of sea ice is associated with near $40 \%$ of total variances in the SLP from spring to fall, in $300 \mathrm{mb}, 500 \mathrm{mb}$ and surface air temperature during summer, while the leading modes of atmosphere variables for the most part only
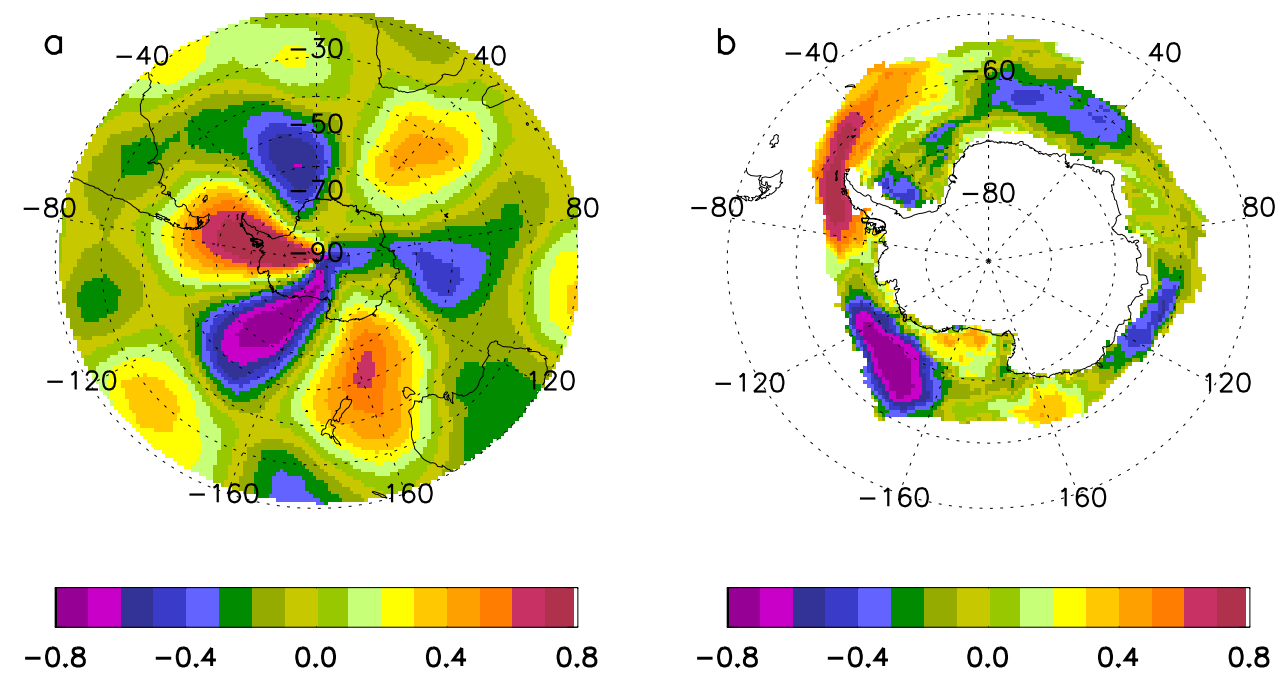

Figure 2. Spatial patterns of the leading SVD mode between (a) winter (JJA) meridional wind anomaly at $300 \mathrm{mb}$ height from $20^{\circ}$ to $90^{\circ} \mathrm{S}$ and (b) sea ice concentration anomaly. This leading mode explains $44 \%$ of total squared covariance between the wind and ice fields. 

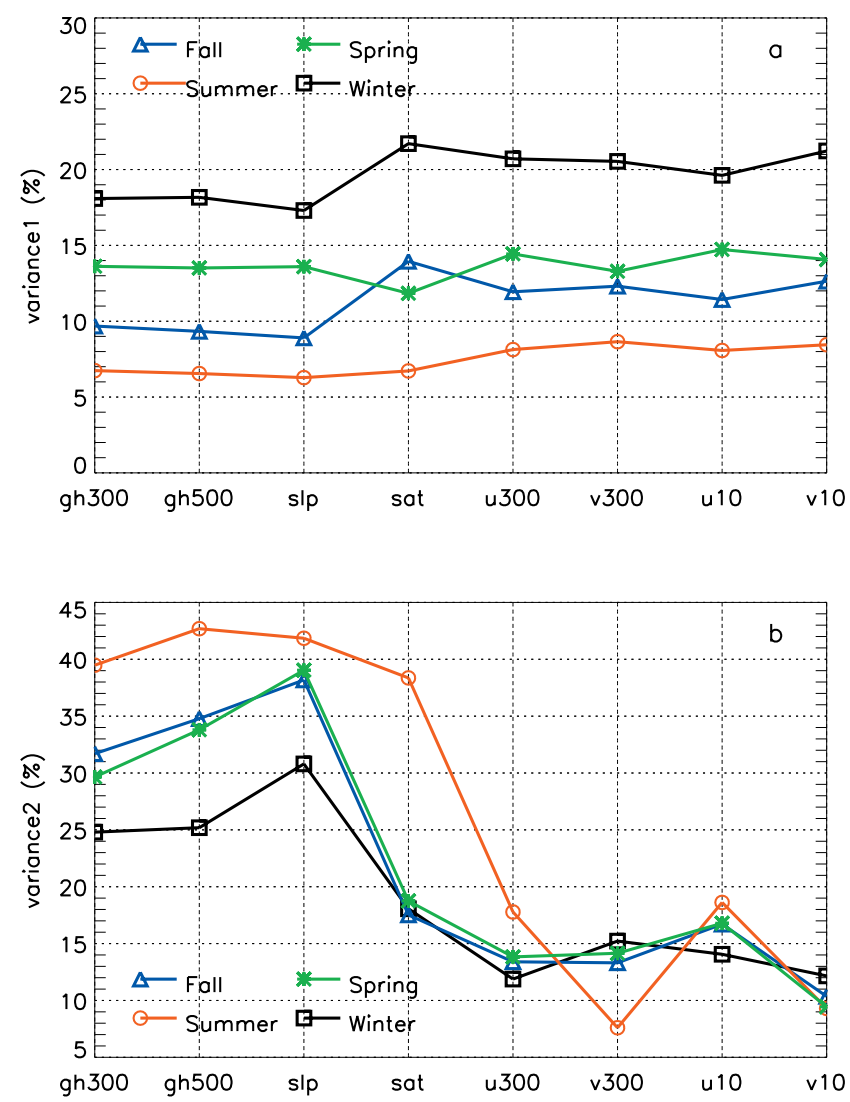

Figure 3. (a) Percentage of the variance of the sea ice field explained by the leading SVD mode of each atmospheric variable as function of seasons. (b) Percentage of the variance of each atmospheric variable explained by the leading SVD mode of the sea ice field as function of seasons.

explain statistically near $20 \%$ of total ice variance during winter. The result clearly suggests the potential importance of sea ice in influencing overlying atmosphere, which has not been examined thoroughly. Though the growth and decay of sea ice is evidently impacted by the atmospheric forcing thermodynamically and dynamically, it is also limited by the oceanic condition. Even in the Antarctic, sea ice cannot grow freely in responding to the atmospheric forcing, the tremendous heat source in the ocean limits the northward expansion of sea ice and creates polynyas. On the other hand, as the boundary condition to the atmosphere, the existence of ice cover could effectively interfere with heat and momentum fluxes at the air-sea interface, and influence the absorption of short wave radiation at the sea surface. These processes directly impact the variability of air temperature and SLP. The lower atmosphere could respond to the changes at the sea surface without much limitation. Sea ice also exhibits a larger variability during summer than during winter. Therefore, the contrast exhibited in Figures 3a and $3 \mathrm{~b}$ is understandable. However, how far the sea ice's influence extends in the atmosphere and how the sea ice impact interacts with existing atmospheric patterns is still yet to be determined in future research.

[15] In summary, the leading mode from SVD analysis captures known climate patterns in the atmosphere-ocean-sea ice system (as shown in Figures 1 and 2), which dominates covariability between the atmosphere and sea ice. However, the SVD analysis is a mathematical tool, which is not designed for separating physical modes. To investigate the impact from individual climate modes on the sea ice field, we need to generate indices best representing these modes.

\section{Variability of the Major Climate Modes 4.1. Indices of Climate Modes}

[16] To construct time series of these four climate modes, we either follow conventions in earlier literatures or choose the atmospheric variables that best represent these modes. PSA, by its nature, appears in pressure fields and has a known relationship with the ENSO variability in the tropics. The PSA index is then defined by monthly $500 \mathrm{mb}$ height anomalies at three anomalous centers in east of New Zealand, the Amundsen Sea and Southwest Atlantic, respectively. This definition, $\operatorname{Index}_{\mathrm{PSA}}=(\mathrm{H} 1+\mathrm{H} 2-\mathrm{H} 3) / 3$, is similar to the definition of PNA in the Northern Hemisphere. Here we use $500 \mathrm{mb}$ heights at $45^{\circ} \mathrm{W} 50^{\circ} \mathrm{S}, 170^{\circ} \mathrm{W}$ $45^{\circ} \mathrm{S}$, and $120^{\circ} \mathrm{W} 67.5^{\circ} \mathrm{S}$ for $\mathrm{H} 1, \mathrm{H} 2$, and $\mathrm{H} 3$, respectively. In response to the ENSO warm events, the PSA pattern consists of a positive anomalous SLP center in the Amundsen Sea (H3) and negative SLP anomalies east of New Zealand (H2) and in South America/South Atlantic (H1). The PSA pattern responds to La Niña events with the opposite phase for all three anomalous centers.

[17] The wave-3 pattern is most profound in meridional winds and pressure fields. We use the principle component of the leading EOF mode in surface monthly meridional wind as the time series of this pattern. The spatial pattern of the leading mode exhibits a well-defined wave- 3 pattern (Figure 4), in which longitudes of the three northerly branches coincide with the zonal positions of the ridges of the wave-3 in 500-hPa fields [van Loon and Jenne, 1972; Raphael, 2004]. Even though this definition is completely different from Raphael's [2004] wave-3 index that is based on $500 \mathrm{mb}$ geopotential height anomalies at three fixed locations, the three northerly branches nicely coincide with longitudinal locations of Raphael's wave-3 centers. The major difference between these two wave- 3 definitions is the latitudinal locations of wave- 3 centers. The maximum centers in the meridional wind definition (near $60^{\circ} \mathrm{S}$ ) are south of the maximum centers of Raphael's wave- 3 (around $49^{\circ} \mathrm{S}$ ). We chose the first one because it has a more direct effect on sea ice fields. Since meridional winds exhibit large variability, the leading mode only takes into account $7 \%$ of the total variance in monthly time series.

[18] The sea level pressure (SLP) anomaly has been used to describe SAM variability [Rogers and van Loon, 1982; Gong and Wang, 1999]. Here we use the principal component of the leading EOF mode in SLP anomaly fields from $20^{\circ}$ to $90^{\circ} \mathrm{S}$ as the SAM index. The leading mode accounts for $28 \%$ of total variance of monthly SLP, which is slightly higher than Gong and Wang [1999] because the time periods considered are different. The spatial pattern reflects out-of-phase SLP anomalies on the Antarctic continent and over the midlatitude ocean (Figure 4).

[19] Last, the index of SAO is defined by subtracting the zonal mean SLP at $50^{\circ} \mathrm{S}$ by the zonal mean SLP at $65^{\circ} \mathrm{S}$ to 
a

$500 \mathrm{mb}$ height anomaly (11/1999)

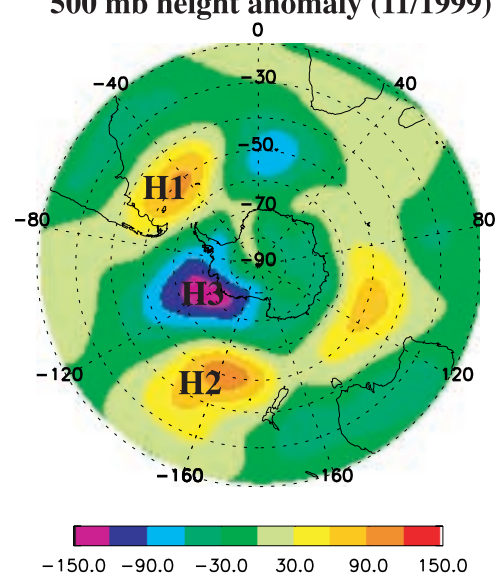

C SAM

(SLP EOF1, 28\% variance)

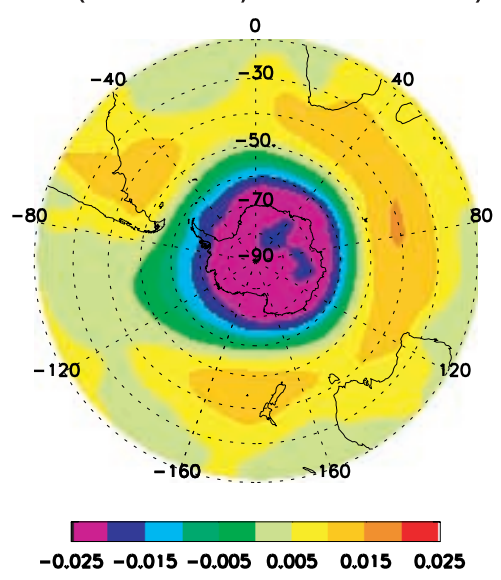

b

WAVE 3

(V EOF1, 7\% variance)

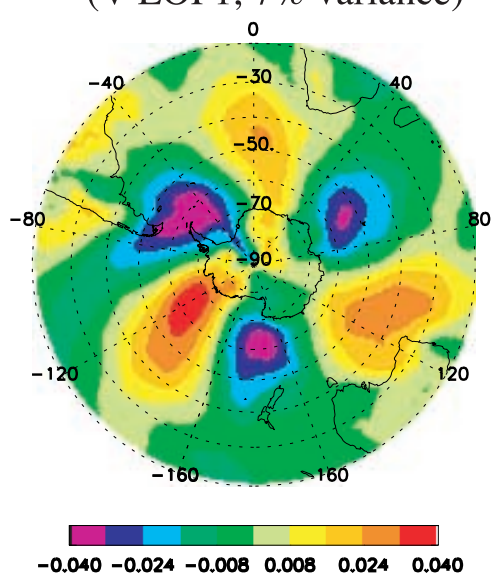

d $\quad$ SAO

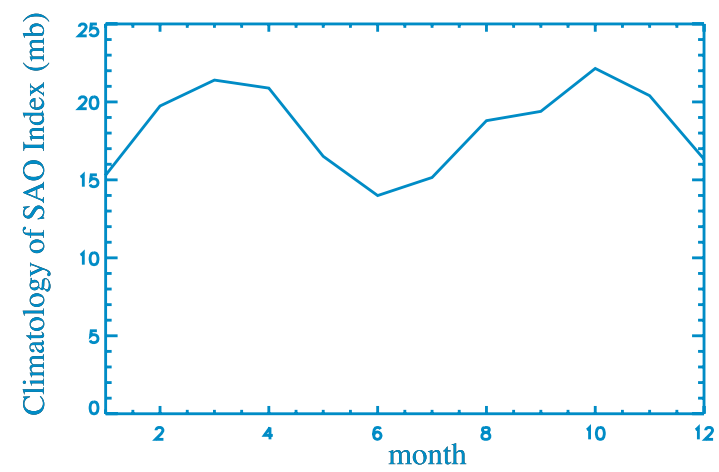

SAO Index $=<$ SLP50S $>-<$ SLP65S $>$

Figure 4. (a) Monthly $500 \mathrm{mb}$ height anomaly (meters) in November 1999 as an example of PSA pattern, (b) wave-3 pattern given by the eigenvector of leading EOF mode of the standardized anomalous surface meridional wind, and (c) SAM as the eigenvector of the leading EOF mode of standardized sea level pressure anomaly fields. The climatology of SAO is displayed in Figure 4d. See text for the definition of each climate mode.

reflect the magnitude of meridional gradient of SLP between these two latitudes. The key characteristic of SAO is its halfyearly cycle. In a harmonic analysis, van den Broeke [1998] found that in the SLP fields the half-yearly cycle dominates in the Antarctic coastal region but the annual cycle dominates on the Antarctic plateau. Therefore, using the SLP at the latitude of $65^{\circ} \mathrm{S}$, which is close to the coast in the eastern Antarctic, best represents the SAO's temporal characteristic. It is also noted that both SAM and SAO are more or less zonally symmetric phenomena. Even the SAM index is defined in the SLP anomaly fields, while the SAO is defined in the mean SLP fields. These two indices share a large amount of variance (will be shown later). The main difference between these two climate modes is that pressure variability over the Antarctic continent largely contributes to the SAM variability but not necessarily to the $\mathrm{SAO}$ variability.

\subsection{Trends}

[20] Significant trends exist in all four climate modes from 1950 to 2003 . To quantify the magnitude of these trends and compare the strength of trends among the indices, time series of these climate modes were standardized and then least-squarely fitted into straight lines. The magnitudes or strength of the trend over 54 years were determined by the difference of the two endpoints of these straight lines divided by the decades. Table 2 presents the magnitude of these trends. Apparently, the trend in SAM is the largest among these indices, followed by SAO.

[21] The strong positive trend in SAM indicates an increasingly lower pressure over Antarctica and higher pressure in midlatitudes, resulting in a strengthened westerly. A previous study [Thompson and Solomon, 2002] has attributed this increasing trend to global warming and the

Table 2. Linear Trends in Standardized Climate Mode Indices and Their Significance Levels

\begin{tabular}{lcccc}
\hline & PSA & Wave 3 & SAM & SAO \\
\hline Linear trend (changes per decade) & 0.175 & -0.098 & 0.346 & 0.282 \\
Significance level of the trends & $99 \%$ & $99 \%$ & $99 \%$ & $99 \%$ \\
\hline
\end{tabular}


Table 3. Cross-Correlation Coefficients and Shared Variance in Parentheses Among Climate Modes for the Period of 1975-2003 ${ }^{\mathrm{a}}$

\begin{tabular}{lcccc}
\hline & PSA & Wave 3 & SAM & SAO \\
\hline PSA & 1 & & & \\
wave 3 & $0.60(36 \%)$ & 1 & & \\
SAM & $0.58(34 \%)$ & $0.28(8 \%)$ & 1 & \\
SAO & $0.59(35 \%)$ & $0.29(8 \%)$ & $0.79(62 \%)$ & 1 \\
\hline
\end{tabular}

${ }^{\mathrm{a}}$ All monthly data were detrended but not filtered.

ozone hole, and also suggested that this trend in SAM is responsible for the rapid surface warming and sea ice retreat in the western Antarctic Peninsula. However, Liu et al. [2004] suggested that both trends in SAM and ENSO cannot account for the total sea ice trend in the western Antarctic Peninsula. The increasing trend in the SAO needs to be treated cautiously, since it could partially come from the spurious long-term reduction of SLP near $65^{\circ} \mathrm{S}$ in the NCEP/NCAR reanalysis data [Hines et al., 2000]. It may also be because of this artificial trend in the SLP, we don't see the weakening of the SAO since 1970 as described in early studies [van Loon et al., 1993; Hurrell and van Loon, 1994]. The positive trend in PSA could mean a stronger Amundsen Sea Low over time and/or stronger high-pressure centers in midlatitudes of the South Pacific and South Atlantic, or both. It also could result from increasingly more/consistent responses to La Niña events in the tropical Pacific [Yuan and Martinson, 2001; Yuan, 2004].

[22] Despite the fact that all climate modes exhibit significant trends, the total sea ice extent in the Antarctic only shows a non-significant trend over the last 30 years of the satellite era [Parkinson, 2004; Vinnikov et al., 2006]. This is because of the large spatial variability in the trends of Antarctic sea ice. Two regions exhibit significant trends in sea ice [Yuan and Martinson, 2000; Liu et al., 2004; Stammerjohn et al., 2008]. The Western Antarctic Peninsula experiences a dramatic sea ice reduction and the western Ross Sea has a significant increase in ice cover since 1978. The new results suggest that these significant trends are associated with decadal changes in the mean state of SAM and the high-latitude responses to ENSO variability [Stammerjohn et al., 2008]. Evidently, owing to the complication of interactions among these climate modes and interactions between sea ice and the ocean beneath and atmosphere above, none of those significant trends in the climate modes can be translated into trends in sea ice.

\subsection{Temporal Variability and Interrelationships of the Climate Modes}

[23] To examine the temporal variability of these climate modes, we conduct power spectral analysis on de-trended and standardized time series of each index. Power spectral densities reveal the energy distribution of these indices as a function of timescales (not shown here). The key result is that the largest energy loading (the highest spectral peak) of each climate mode occurs at different frequencies, which differentiates one mode from others. The largest energy loading in both PSA and wave-3 occurs in 3- to 4-year periods, likely associated with the ENSO variability. Decadal variability dominates the spectral distribution of the SAM index. Since we examine the monthly time series, SAM's dominant peak at 10-day period [Thompson and Wallace, 2000] does not present in the spectrum. The half-year cycle overwhelmingly dominates the SAO spectrum.

[24] Even though these climate modes are formed by different physical or dynamical processes; and their indices are defined in different atmospheric variables and have different spectral distributions, they are hardly independent from each other. The interrelationships of these modes are examined by cross correlations (Table 3 ) and cross-spectral analysis (Figure 5). The largest co-variability occurs between SAM and SAO since they represent more-or-less zonally symmetric phenomenon. They share $62 \%$ of variance (Table 3). Most of the shared variance comes from the variability in annual, 4-year and decadal periods based on the significant cross-spectrum peaks (Figure $5 b$ ). The oscillations of pressure anomalies in Antarctica and midlatitudes (SAM's variability) also modify the meridional pressure gradient that is used to define SAO. So the high correlation is expected. However, these two indices have quite a difference at the seasonal timescale in their individual spectra, indicating their independent characteristics in the atmospheric circulation. PSA and wave-3, the two zonally asymmetric modes, share $36 \%$ of variance. The large covariability occurs in 3- to 4-year periods (Figure 5a) and in the ADP region. The wave-3 is rather independent from SAM and SAO (Figures 5e and 5f). PSA shares unnegligible amount of variance with SAM at interannual and decadal timescales (Figure 5c), suggesting an impact from PSA to SAM. This impact is also visible in the spatial pattern of SAM, in which the annular pattern is disturbed in the Amundsen Sea likely owing to the interference by PSA (Figure 4).

\subsection{Relative Importance}

[25] Since these climate modes are defined from different atmospheric variables, the relative importance of each mode in the atmosphere is evaluated by calculating the regressions of these modes on the sea level pressure field. Clearly, PSA dominates the pressure field in the South Pacific with a pattern of strong Amundsen Sea Low and an anomalous high-pressure center east of New Zealand. The regressions associated with the wave- 3 index show a similar spatial pattern but with three more evenly distributed positive centers around the globe. Still the strongest branch of the wave-3 pattern occurs in the South Pacific, indicating the interaction between the PSA and wave-3 pattern. Both PSA and wave-3 have little impact on the pressure field over the Antarctic continent. SAO has an annular shape of spatial distribution and has a relatively stronger influence in the southwest Pacific and South Indian Ocean. It also strongly influences the SLP in the western Antarctic continent, particularly along the Southeast Pacific coast. The regressions on SAM index are similar to that of SAO but have relatively weaker shares in the SLP variability than the SAO (Figure 6). The correlations between these indices and the SLP provide conformable patterns (not shown).

\section{Impacts on Sea Ice}

[26] Nevertheless, the impacts from these climate modes on sea ice are examined by correlation coefficients. The 

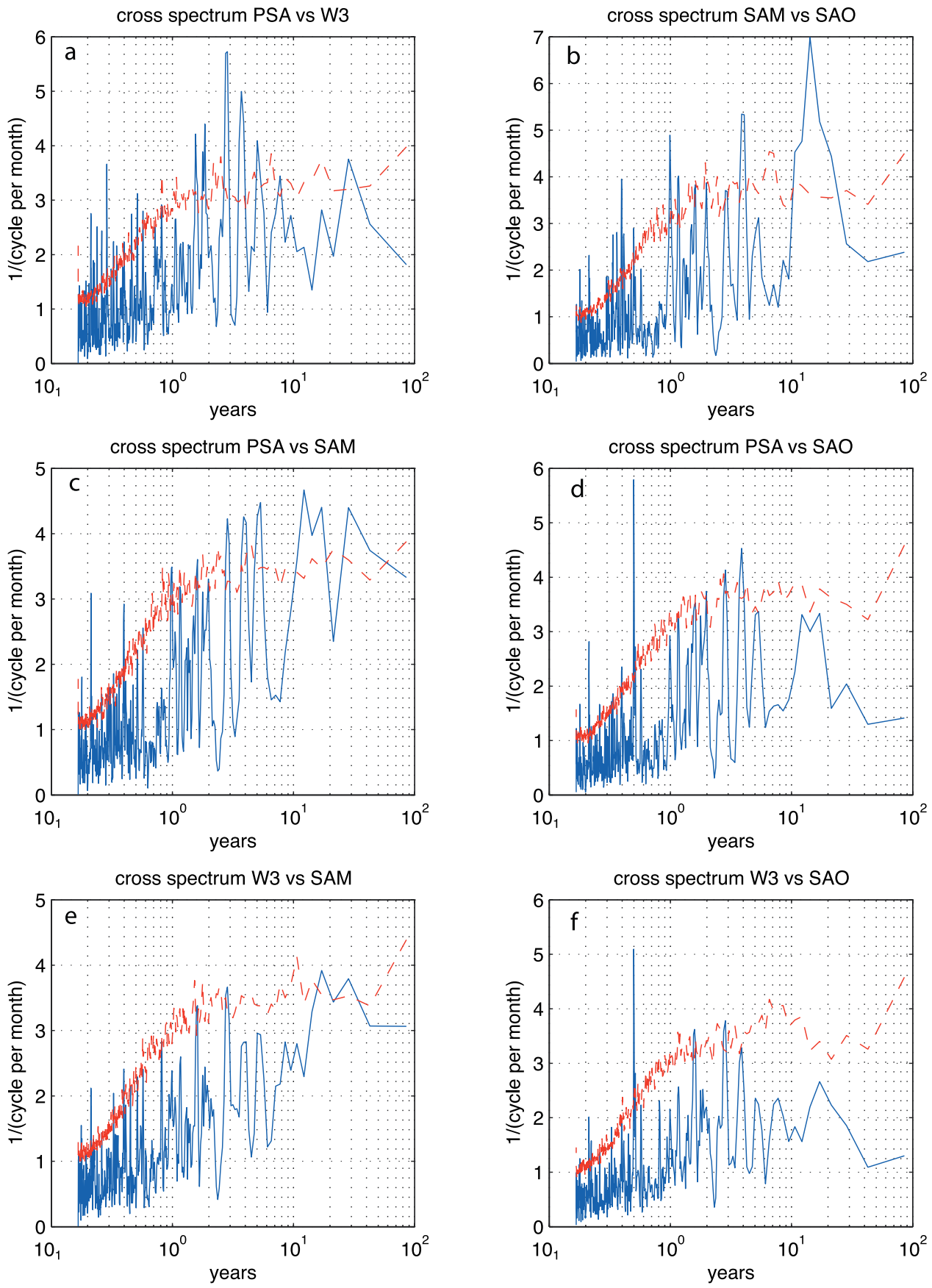

Figure 5. Cross spectra between (a) PSA and wave-3, (b) SAM and SAO, (c) PSA and SAM, (d) PSA and SAO, (e) wave-3 and SAM, and (f) wave-3 and SAO. The 53-year monthly time series of these indices were standardized and detrend before calculating the cross spectra. Dashed lines are the $95 \%$ confidence level based on the test of 200 red noise that preserve the redness of each pair of original time series.

long-term trend is removed from each indices and sea ice concentration anomalies at each grid point before the correlation calculation. To focus on interannual and longer timescales, we also filter the monthly time series of climate indices and sea ice anomalies with a Gaussian filter that has a filter width of 13-month. Figure 7 displays the correlation coefficients between these modes and sea ice when ice lags 2 months. Apparently, PSA is strongly correlated with the Antarctic Dipole in sea ice in the western hemisphere. This correlation pattern results from the variability of the Amundsen Sea Low. The anomalies of this pressure center provides out-of-phase poleward heat transport anomalies east of the Ross Sea and in the Weddell Sea that creates the opposite sea ice/temperature anomalies in these two regions simultaneously [Yuan, 2004]. As the anomalous pressure center associated with the Amundsen Sea Low is the largest action center in Southern Ocean pressure field, the Antarctic Dipole represents the largest interannual variability in the 

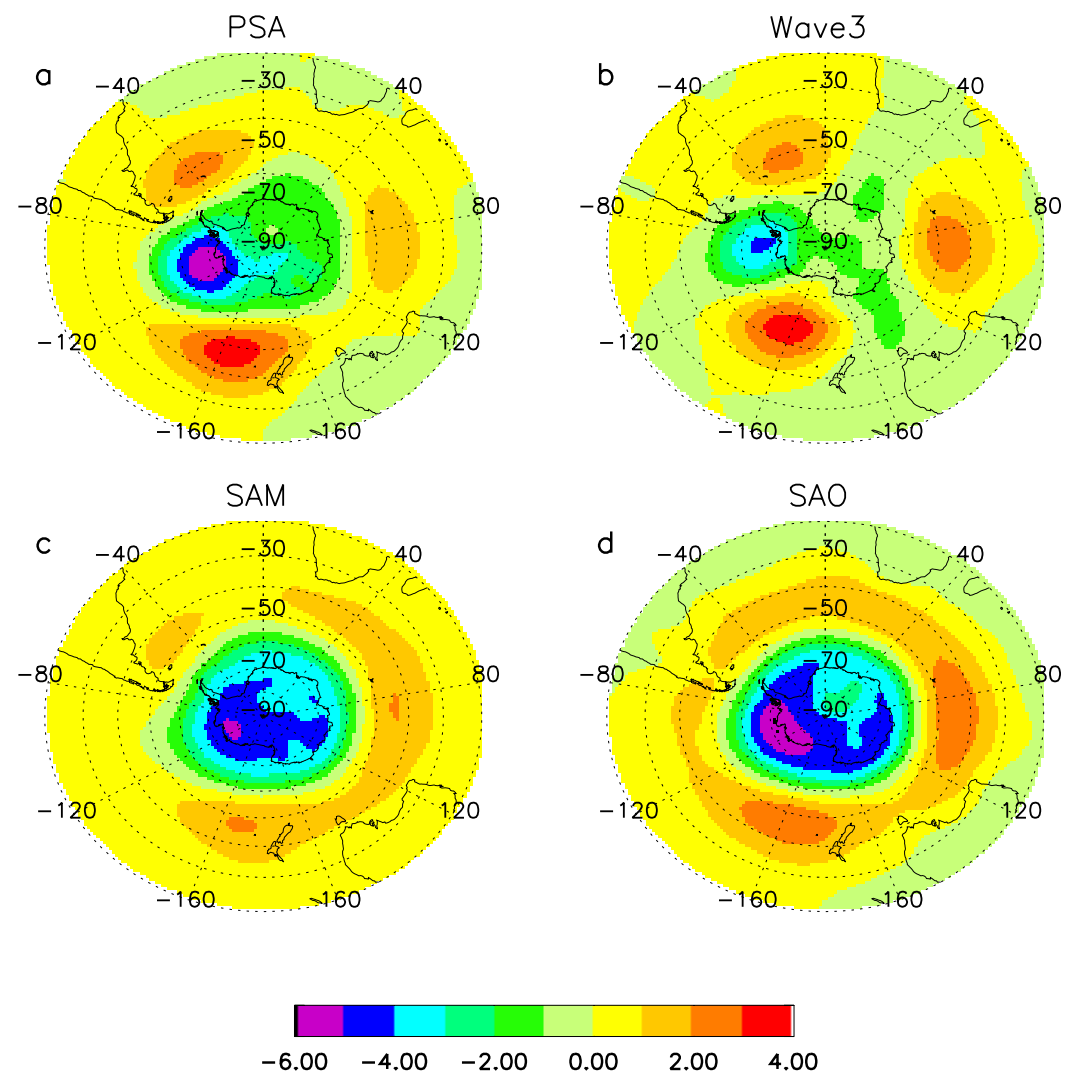

Figure 6. Linear regression coefficients of (a) PSA, (b) wave-3, (c) SAM, and (d) SAO on sea level pressure. All climate indices are standardized before the regression. The unit is mb per 1 standard deviation of each index.

sea ice and surface temperature fields. The second large impact comes from the wave-3 pattern. It is noted that the impact from the wave- 3 is not evenly distributed among the three branches. The correlation pattern from the wave- 3 is quite similar to PSA in the western hemisphere, which is much stronger than the branch in the Indian Ocean, suggesting a potential reinforcement between these two modes in the region. PSA and wave-3 pattern generally have higher correlations with sea ice than SAM and SAO do, particularly in the western hemisphere. While the influences from SAM and SAO on sea ice are more evenly distributed around Antarctica, they are relatively more important in the South Indian Ocean.

[27] We further quantify the influences from these climate modes by calculating correlations from ice lagging 6 months to leading 6 months and then conducting local and field significance tests (for details, see Yuan and Martinson [2000]) for each correlation map. First, the significance of correlation at each grid point is evaluated by taking account of autocorrelation existing in both correlating time series (local significance test). Second, we count the percentage of the grid points that pass the local significance test at the 99\% confidence level for each correlation map (e.g., each time lag). These percentages derived from real data are then compared with the same calculation based on the correlations between 1000 red noise time series and sea ice (field significance test). The purpose of the field significance test is to determine if real data contain more significant correlations than expected from random noise (red color) owing to some spatial coherence in the ice field. Figure 8 shows that PSA and wave- 3 exhibit more significant correlations than expected from random noise (the dashed line) from ice lags 6 months to ice leads 2 months (leads 6 months for PSA). SAO is slightly behind PSA and wave-3 on the number of significant correlations, but still consistently higher than what is expected from red noise series. SAM only makes above the $95 \%$ confidence level when ice lags 2 months. It clearly shows that SAM has relatively less influence on sea ice than other climate patterns. In addition, another point stands out from Figure 8. The highest percentage of significant correlations occur at an ice lag of 2 months for all four modes, indicating that sea ice usually responds to large-scale atmospheric anomalies with a 2-month delay. That indicates the likelihood of causality relationships between the climate indices and sea ice.

[28] It is worth noting that these assessments reflect the impacts from interannual variability of the climate modes without long-term trends and are based on the entire Antarctic, which may not be applicable to individual locations. For example, sea ice in the western Antarctic Peninsula exhibits a strong declining trend [Yuan and Martinson, 2000; Liu et al., 2004; Stammerjohn et al., 2008], even though the trend in the entire Antarctic ice extent is slightly increased [Parkinson, 2004; Vinnikov et al., 2006]. Thompson and Solomon [2002] suggested that the positive trend in SAM (toward the stronger circumpolar flow) has contributed substantially to the surface warming and sea ice retreat in the region, even though it cannot explain the total trend in 

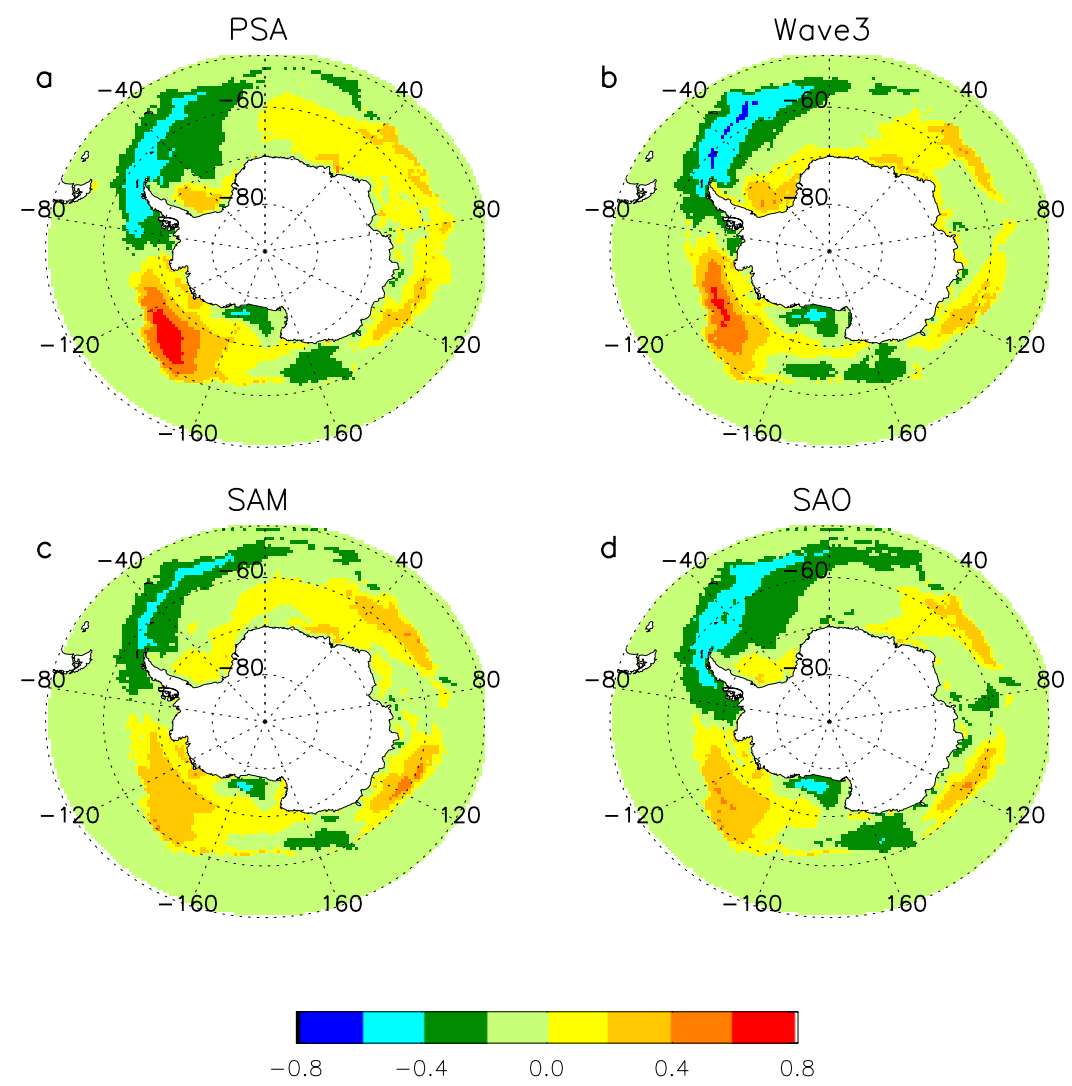

Figure 7. Correlation coefficients between Antarctic sea ice concentration anomalies (lag 2 months) and time series of the (a) PSA, (b) Wave-3 pattern, (c) SAM, and (d) SAO.

sea ice [Liu et al., 2004]. This relationship between the trends in SAM and sea ice is very localized since the Antarctic Peninsula extends further north than any other parts of the Antarctic and is more directly exposed to the changes in the westerly associated with the SAM variability. Moreover, these assessments may not represent decadal variability in the Southern Ocean owing to the limits of the time series.

[29] Besides interannual variability, these climate modes have significant subannual/seasonal variabilities. As mentioned before, SAM appears to be strong in the summer. The wave- 3 pattern is more profound in winter and has an eastwest seasonal migration of its ridge and trough [Raphael, 2004]. SAO, by its nature, has the largest signal in spring and fall. To include subannual variability, we repeat the correlation with all unfiltered monthly time series. The resulting correlation patterns are similar to the patterns in Figure 7 but with much weaker correlation coefficients for all modes, suggesting that subannual variabilities introduce more noise than signal to the relationships between these atmospheric modes and sea ice.

\section{Summary and Discussion}

[30] In this study, we examine the main characteristics of four major climate modes in the southern hemisphere and their impact on Antarctic sea ice. These four climate modes, PSA, wave-3 pattern, SAM, and SAO, are well-established climate patterns in the southern hemisphere from mid to high latitudes. They are formed by different physical or dynamic processes with distinct spatial patterns and unique temporal characteristics. Power spectral analyses applied to the individual time series of these modes reveal their temporal characteristics. The dominant variability (or the largest energy loading) in both PSA and the wave-3 pattern occurs at 3- to 4-year periods, likely associated with ENSO teleconnection. Decadal variability dominates the SAM monthly time series, while the half-year cycle overwhelmingly dominates the SAO spectrum. Spatially, PSA and wave-3 each represent comparable amounts of variability in the Antarctic SLP field, while PSA has a larger share of variance in the South Pacific than wave-3 does. These two patterns claim more variance in the SLP field than the other two modes, particularly in the western hemisphere. SAM and SAO have relatively stronger impacts on the SLP in the midlatitude oceanic regions and the western Antarctic continent, particularly along the South Pacific coast (Figure 6). Although the regression patterns from SAM and SAO are quite similar, SAO has more variance than SAM in the monthly SLP field.

[31] Despite the fact that all these modes are generated differently and defined in different atmospheric variables, they actively interact with each other within the climate system of the southern hemisphere. The stronger branches of wave- 3 in the western hemisphere (Figure 6) and crossspectral analysis suggest that PSA positively interacts with the wave- 3 pattern at the interannual timescale, and in the ADP region. PSA also affects SAM at interannual and decadal timescales revealed by both the cross-spectral analysis (Figure 5) and their spatial patterns. Distinctly 


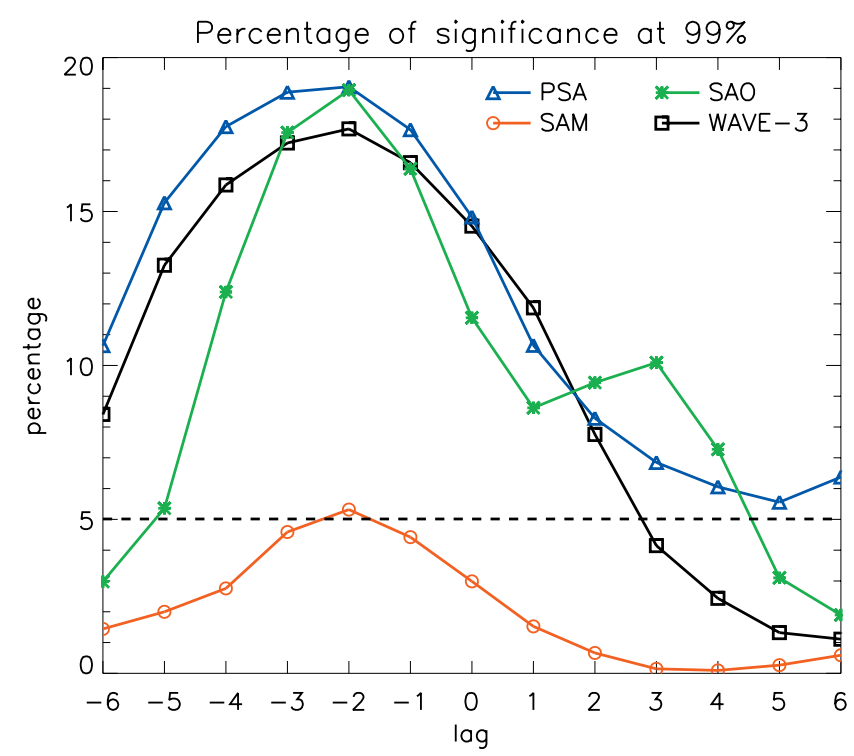

Figure 8. Percentage of grid points with significant correlation at $99 \%$ confidence level (the local significance test) in each correlation map as a function of climate modes and lagging months. Positive lags represent ice leading climate modes. The dashed line indicates what percentage of grid points with significant correlation can be expected from red noise series at the $95 \%$ confidence level (the field significance test). One thousand red noise series with the redness of the SAM time series were used in the field significance test. Using the redness of other climate indices changes the dashed line slightly but not changes the main results.

different individual spectral distributions from SAM and SAO do not prevent them from sharing large amounts of variance $(62 \%)$ at subseasonal, annual, interannual and decadal timescales as revealed by the cross-spectral and cross correlation analyses. These are due to the fact that they both reflect meridional variations in the pressure field. Even the time series of these climate mode indices are defined in the atmospheric variables that best represent their unique characteristics. They could never be cleanly separated from the influences of other modes. Therefore, understanding the interaction among these climate modes becomes crucial for understanding the sea ice variability. For example, a recent study [Stammerjohn et al., 2008] suggests that the impacts from SAM and ENSO on sea ice near the western Antarctic Peninsula are out of phase in the 1980s but in phase in the 1990s, which results in a significant decreasing trend in the total ice cover days over the satellite era. van den Broeke [2000b] also shows that a pronounced wave-3 pattern interferes with the northward movement of SAO during its expansion phases (austral spring and fall). Further studies on the interaction among these climate modes are needed to advance our understanding of the climate variability from seasonal to interannual timescales.

[32] These climate modes collectively influence the sea ice variability in the Antarctic. Indeed, the covariability between the atmosphere and sea ice are dominated by these known climate modes as suggested by the leading SVD modes between various atmospheric variables and sea ice anomalies. Among these four climate modes, PSA, the pattern more directly related to the ENSO variability, has the largest influence on sea ice and directly generates the ADP anomalies in the western hemisphere. It is followed by the wave- 3 pattern with a very similar impact pattern in the ADP regions. Moreover, this ADP out-of-phase sea ice anomalous pattern is also related to SAM and SAO variability. These results suggest that the ENSO teleconnection is a key factor influencing Antarctic sea ice at the interannual timescale. The ENSO teleconnection could interact with other climate modes and create the largest anomaly in the atmosphere. Consequently, it creates the largest sea ice anomalies in the ADP regions. Positive feedback between the atmosphere, ocean and sea ice could further reinforce this climate anomaly, so that it stands out as the largest coupled mode in the Antarctic climate system. Moreover, sea ice responds to this ENSO-related atmospheric anomaly with a 2-month delay, in contrast to ice floe or ice edge's response to synoptic atmospheric forcing at much shorter timescales.

[33] Another observed and modeled pattern in the Antarctic SST, sea ice and sea surface height is the propagating wave-2 pattern reported as the Antarctic Circumpolar Wave (ACW) in earlier studies [White and Peterson, 1996; Jacobs and Mitchell, 1996; Qiu and Jin, 1997]. Indeed, climate anomalies in the western Antarctic tend to propagate eastward at interannual [White and Peterson, 1996] to intraseasonal timescales [Baba et al., 2006]. However, its circumpolar nature is debatable. Yuan and Martinson [2000] used a complex EOF analysis to show that the sea ice edge anomaly propagates eastward in the central/eastern Pacific and Weddell Gyre, though not continuously through the Drake Passage, and the propagating signal becomes insignificant and less consistent in the Indian Ocean and Western Pacific. Figure 1 of White and Peterson [1996] reveals that the largest SST and sea ice edge anomalies always occur near $150^{\circ} \mathrm{W}$ accompanied by opposite phased anomalies near $60^{\circ} \mathrm{W}$, which is the nature of a standing wave: such as the ADP. As these anomalies propagate out of the action centers of the standing wave, they are weakened. In the Indian Ocean, the propagating signals are barely traceable, which is consistent with the finding of Yuan and Martinson [2000]. Venegas [2003] analyzed surface atmospheric variables and sea ice data. She found that most of ACW's variance comes from a linear combination of a propagating wave- 3 pattern with a periodicity of 3 years and a propagating wave- 2 pattern with a periodicity of 5 years. The wave-3 pattern originates from the atmospheric standing wave-3 pattern and propagates eastward in the Pacific and Indian Ocean but not in the Atlantic Ocean. The propagating wave- 2 pattern is only pronounced in the western hemisphere and is interrupted in the eastern Atlantic and Indian Ocean. The circumpolar appearance of the ACW only appears when wave- 2 is linearly combined with the wave-3 pattern. Moreover, Venegas [2003] pointed out that the constructive or destructive interference of the two modes with different periodicities and wavelengths generates the observed irregular fluctuations of the ACW. In an analysis of the surface air temperature derived from satellite observations, Comiso [2000] also found that the predominant propagating mode is a wave- 3 pattern instead of a wave- 2 
pattern. In this synthesis of these earlier studies, we believe that the ADP in the western hemisphere, which has the same wavelength as the ACW, is the origin of ENSO-related anomalies in the Antarctic surface temperature and sea ice fields. Suggested mechanisms of this tropical-polar teleconnection and the mechanisms that create the ADP have been discussed in detail by Yuan [2004]. The ACC advection and air-sea interaction suggested by early studies [Qiu and Jin, 1997; White et al., 1998; Cai et al., 1999; Venegas, 2003] propagate these anomalies eastward. The atmospheric standing wave-3, as discussed in this study, also creates anomalies in ocean and sea ice of the Antarctic circumpolar region. These anomalies are also propagated eastward under similar mechanisms [Christoph et al., 1998]. The combination of anomalies from ENSO and wave-3 as well as the airsea interaction within the polar climate system give the appearance of a propagating ACW in the Antarctic. Because of this nature of the ACW, it is not identified in this study as a climate mode.

[34] One of the interesting results is that all climate modes defined in this study have significant linear trends during the study period. However, the total sea ice extent in the Antarctic only exhibits a nonsignificant trend [Parkinson, 2004]. That brings up an obvious question: why do climate modes not have an impact on the trend in the total sea ice extent? It is noticed that the trend in Antarctic sea ice has a large regional variation. The sea ice in the western Antarctic Peninsula and Bellingshausen Sea experiences a dramatic decline, while the sea ice in the western Ross Sea has a significant increase. The total sea ice extent averages out these two opposite trends. This does not mean that Antarctic sea ice isn't affected by the long-term climate change in the atmosphere. As pointed out by Stammerjohn et al. [2008], the increasing positive SAM in phase with the impact from La Nina events causes early retreat and late advance of sea ice in the western Antarctic Peninsula region. The average days per year of ice cover are shortened by about 85 days since 1979. Regardless of the trend in the total sea ice extent, this regional reduction of sea ice cover potentially poses a threat to ice shelf and ice sheet in the western Antarctic. Less sea ice cover, particularly during the cold seasons when SST and air temperature have large differences, allows the ocean to vent an enormous amount of heat to the atmosphere and warms air temperature in the region. Moreover, a prolonged ice-free season permits the ocean to absorb more shortwave radiation. Does this warmer surface water melt the ice shelf from below or does it reduce the vertical mixing resulting in less heat from the subsurface layer entering the mixed layer? The combined impact from different climate modes on sea ice and the feedback of these impacts are still not well understood and need further study.

[35] Acknowledgments. This study is supported by the National Ocean and Atmosphere Administration through grant NA030AR4320179, by the National Aeronautics and Space Administration through grant NAG12586, and by National Science Foundation through grant OPP02300284. The authors appreciate the comments from two reviewers and from Associate Editor J. Comiso. Discussions with D. Martinson were very helpful.

\section{References}

Baba, K., S. Monibe, N. Kimura, and M. Wakatsuchi (2006), Intraseasonal variability of sea-ice concentration in the Antarctic with particular emphasis on wind effect, J. Geophys. Res., 111, C12023, doi:10.1029/2005JC003052.
Bretherton, C. S., C. Smith, and J. M. Wallace (1992), An intercomparison of methods for finding coupled patterns in climate data, J. Clim., 5, 541560, doi:10.1175/1520-0442(1992)005<0541:AIOMFF $>2.0 . \mathrm{CO} ; 2$

Cai, W., P. G. Baines, and H. B. Gordon (1999), Southern mid- to highlatitude variability, a zonal wavenumber-3 pattern, and the Antarctic Circumpolar Wave in the CSIRO coupled model, J. Clim., 12, 30873104.

Christoph, M., T. P. Barnett, and E. Roeckner (1998), The Antarctic Circumpolar Wave in a coupled ocean-atmosphere GCM, J. Clim., 11, 16591672, doi:10.1175/1520-0442(1998)011<1659:TACWIA>2.0.CO;2.

Comiso, J. C. (2000), Variability and trends in the Antarctic surface temperature from in situ and satellite infrared measurements, J. Clim., 13, $1674-$ 1696, doi:10.1175/1520-0442(2000)013<1674:VATIAS $>2.0 . C O ; 2$

Comiso, J. C., D. J. Cavalieri, C. L. Parkinson, and P. Gloersen (1997), Passive microwave algorithms for sea ice concentration: A comparison of two techniques, Remote Sens. Environ., 60(3), 357-384, doi:10.1016/ S0034-4257(96)00220-9.

Enomoto, H., and A. Ohmura (1990), The influence of atmospheric halfyearly cycle on the sea ice extent in the Antarctic, J. Geophys. Res., 95(C6), 9497-9511, doi:10.1029/JC095iC06p09497.

Garreaud, R. D., and D. S. Battisti (1999), Interannual (ENSO) and interdecadal (ENSO-like) variability in the Southern Hemisphere tropospheric circulation, J. Clim., 12, 2113-2123, doi:10.1175/1520-0442(1999) 012<2113:IEAIEL $>2.0$. CO;2.

Gong, D., and S. Wang (1999), Definition of Antarctic oscillation index, Geophys. Res. Lett., 26, 459-462, doi:10.1029/1999GL900003.

Hall, A., and M. Visbeck (2002), Synchronous variability in the Southern Hemisphere atmosphere, sea ice, and ocean resulting from the annular mode, J. Clim., 15, 3043-3057, doi:10.1175/1520-0442(2002)015<3043: SVITSH $>2.0 . \mathrm{CO} ; 2$.

Harangozo, S. A. (2000), A search for ENSO teleconnection teleconnections in the west Antarctic Peninsula climate in austral winter, Int. J. Climatol., 20, 663-678, doi:10.1002/(SICI)1097-0088 (200005) 20:6<663::AID-JOC493>3.0.CO;2-I.

Hines, K. M., D. H. Bromwich, and G. J. Marshall (2000), Artificial surface pressure trends in the NCEP-NCAR reanalysis over the southern ocean and Antarctica, J. Clim., 13, 3940-3952, doi:10.1175/1520-0442(2000) 013<3940:ASPTIT>2.0.CO;2.

Hurrell, J. W., and H. van Loon (1994), A modulation of the atmospheric annual cycle in the Southern-Hemisphere, Tellus, Ser. A, 46(3), 325-338.

Jacobs, G. A., and J. L. Mitchell (1996), Ocean circulation variations associated with the Antarctic Circumpolar Wave, Geophys. Res. Lett., 23, 2947-2950, doi:10.1029/96GL02492.

Kalnay, E., et al. (1996), The NCEP/NCAR 40-year reanalysis project, Bull. Am. Meteorol. Soc., 77, 437-471, doi:10.1175/1520-0477(1996) 077<0437:TNYRP $>2.0 . \mathrm{CO} ; 2$

Karoly, D. J. (1989), Southern Hemisphere circulation features associated with El Niño-Southern Oscillation events, J. Clim., 2, 1239-1252, doi:10.1175/1520-0442(1989)002<1239:SHCFAW>2.0.CO;2.

Kiladis, G. N., and K. C. Mo (1998), Interannual and intraseasonal variability in the Southern Hemisphere, in Meteorology of the Southern Hemisphere, edited by D. J. Karoly and D. G. Vincent, Meteorol. Monogr., 27, 307-336.

Kistler, R., et al. (2001), The NCEP-NCAR 50-year reanalysis: Monthly means CD-ROM and documentation, Bull. Am. Meteorol. Soc., 82, 24.7-268.

Kwok, R., and J. C. Comiso (2002), Southern Ocean climate and sea ice anomalies associated with the Southern Oscillation, J. Clim., 15, 487501, doi:10.1175/1520-0442(2002)015<0487:SOCASI >2.0.CO;2.

Lefebvre, W., H. Goosse, and R. Timmermann (2004), Influence of the Southern Annular Mode on the sea ice(ocean system, J. Geophys. Res., 109(C9), C09005, doi:10.1029/2004JC002403.

Liu, J., X. Yuan, D. Rind, and D. G. Martinson (2002), Mechanism study of the ENSO and southern high latitude climate teleconections, Geophys. Res. Lett., 29(14), 1679, doi:10.1029/2002GL015143.

Liu, J., J. A. Curry, and D. G. Martinson (2004), Interpretation of recent Antarctic sea ice variability, Geophys. Res. Lett., 31, L02205, doi:10.1029/2003GL018732.

Lorenz, J. D., and D. L. Hartmann (2001), Eddy-zonal flow feedback in the Southern Hemisphere, J. Atmos. Sci., 58, 3312-3327, doi:10.1175/15200469(2001)058<3312:EZFFIT>2.0.CO;2

Martinson, D. G., and R. A. Iannuzzi (2003), Spatial/temporal patterns in Weddell gyre characteristics and their relationship to global climate, J. Geophys. Res., 108(C4), 8083, doi:10.1029/2000JC000538.

Mo, K. C., and R. W. Higgins (1998), The Pacific(South America modes and tropical convection during the Southern Hemisphere winter, Mon. Weather Rev., 126, 1581-1596, doi:10.1175/1520-0493(1998)126<1581: TPSAMA $>2.0 . \mathrm{CO} ; 2$.

Parkinson, C. L. (2004), Southern Ocean sea ice and its wider linkages: Insights revealed from models and observations, Antarct. Sci., 16(4), 387-400, doi:10.1017/S0954102004002214. 
Qiu, B., and F. F. Jin (1997), Antarctic circumpolar waves: An indication of ocean-atmosphere coupling in the extratropics, Geophys. Res. Lett., 24 2585-2588, doi:10.1029/97GL02694.

Raphael, M. N. (2004), A zonal wave 3 index for the Southern Hemisphere, Geophys. Res. Lett., 31, L23212, doi:10.1029/2004GL020365.

Renwick, J. A. (2002), Southern Hemisphere circulation and relations with sea ice and sea surface temperature, J. Clim., 15, 3058-3068, doi:10.1175/1520-0442(2002)015<3058:SHCARW>2.0.CO;2.

Rind, D., M. Chandler, J. Lerner, D. G. Martinson, and X. Yuan (2001), The climate response to basin-specific changes in latitudinal temperature gradients and the implications for sea ice variability, J. Geophys. Res., 106(D17), 20,161-20,173, doi:10.1029/2000JD900643.

Rogers, J. C., and H. van Loon (1982), Spatial variability of sea-level pressure and $500 \mathrm{mb}$ height anomalies over the Southern-Hemisphere, Mon. Weather Rev., 110, 1375-1392, doi:10.1175/1520-0493(1982) $110<1375$ :SVOSLP $>2.0 . \mathrm{CO} ; 2$.

Simmonds, I., and T. H. Jacka (1995), Relationships between the interannual variability of Antarctic sea ice and the Southern Oscillation, J. Clim., 8, 637-647, doi:10.1175/1520-0442(1995)008<0637:RBTIVO >2.0.CO;2.

Simmonds, I., and D. A. Jones (1998), The mean structure and temporal variability of the semiannual oscillation in the southern extratropics, Int. J. Climatol., 18, 473-504, doi:10.1002/(SICI)1097-0088(199804)18:5< 473::AID-JOC266>3.0.CO;2-0.

Stammerjohn, S. E., M. R. Drinkwater, R. C. Smith, and X. Liu (2003), Iceatmosphere interaction during sea-ice advance and retreat in the western Antarctic Peninsula region, J. Geophys. Res., 108(C10), 3329 doi:10.1029/2002JC001543.

Stammerjohn, S. E., D. G. Martinson, R. C. Smith, X. Yuan, and D. Rind (2008), Trends in Antarctic annual sea ice retreat and advance and their relation to El Niño-Southern Oscillation and Southern Annular Mode variability, J. Geophys. Res., 113, C03S90, doi:10.1029/2007JC004269.

Thompson, D. W. J., and S. Solomon (2002), Interpretation of recent Southern Hemisphere climate changes, Science, 296, 895-899, doi:10.1126/ science. 1069270 .

Thompson, D. W. J., and J. M. Wallace (2000), Annular modes in the extratropical circulation, part I, Month-to-month variability, J. Clim., 13, 1000-1016, doi:10.1175/1520-0442(2000)013<1000:AMITEC> 2.0.CO;2.

van den Broeke, M. R. (1998), The semi-annual oscillation and Antarctic climate. Part I: Influence on near surface temperature (1957-79), Antarct. Sci., 10(2), 175-183.

van den Broeke, M. R. (2000a), The semi-annual oscillation and Antarctic climate. Part 4: A note on sea ice cover in the Amundsen and Bellingshausen Seas, Int. J. Climatol., 20, 455-462, doi:10.1002/(SICI)10970088(20000330)20:4<455::AID-JOC482>3.0.CO;2-M.

van den Broeke, M. R. (2000b), On the interpretation of Antarctic temperature trends, J. Clim., 13, 3885-3889, doi:10.1175/1520-0442[2000] 013<3885:OTIOAT>2.0.CO;2.

van Loon, H. (1967), The half-yearly oscillation in the middle and high latitudes and the coreless winter, J. Atmos. Sci., 24, 472-486, doi:10.1175/1520-0469(1967)024<0472:THYOIM>2.0.CO;2. van Loon, H. (1972), Wind in the Southern Hemisphere, in Meteorology of the Southern Hemisphere, Meteorol. Monogr., vol. 35, pp. 59-86, Am. Meteorol. Soc., Boston, Mass.

van Loon, H. (1984), The Southern Oscillation, part 3, Associations with the trades and with the trough in the westerlies of the South Pacific Ocean, Mon. Weather Rev., 112, 947-954, doi:10.1175/15200493(1984)112<0947:TSOPIA>2.0.CO;2.

van Loon, H., and R. L. Jenne (1972), Zonal harmonic standing waves in the Southern Hemisphere, J. Geophys. Res., 77(6), 992-1103, doi:10.1029/JC077i006p00992.

van Loon, H., J. W. Kidson, and A. B. Mullan (1993), Decadal variation of the annual cycle in the Australian dataset, J. Clim., 6, 1227-1231, doi:10.1175/1520-0442(1993)006<1227:DVOTAC >2.0.CO;2.

Venegas, S. A. (2003), The Antarctic Circumpolar Wave: A combination of two signals?, J. Clim., 16, 2509-2525, doi:10.1175/1520-0442 (2003)016<2509:TACWAC $>2.0 . C O ; 2$

Vinnikov, K. Y., D. J. Cavalieri, and C. L. Parkinson (2006), A model assessment of satellite observed trends in polar sea ice extents, Geophys. Res. Lett., 33, L05704, doi:10.1029/2005GL025282.

Walland, D., and I. Simmonds (1999), Baroclinicity, meridional temperature gradients, and the southern semiannual oscillation, J. Clim., 12, 3376-3382, doi:10.1175/1520-0442(1999)012<3376:BMTGAT $>2.0$. $\mathrm{CO} ; 2$.

Watkins, A. B., and I. Simmonds (1999), A late sprint surge in the open water of the Antarctic, Geophys. Res. Lett., 26, 1481-1484, doi:10.1029/ 1999GL900292.

White, B. W., and R. G. Peterson (1996), An Antarctic circumpolar wave in surface pressure, wind, temperature and sea ice extent, Nature, 380, 699702, doi:10.1038/380699a0.

White, B. W., C. Li, and T. Chang-Kou (1998), Coupling of biennial oceanic Rossby waves with the overlying atmosphere in the Pacific Basin, J. Phys. Oceanogr., 28, 1236-1251, doi:10.1175/1520-0485(1998) $028<1236$ :COBORW $>2.0 . \mathrm{CO} ; 2$.

Yuan, X. (2004), ENSO-related impacts on Antarctic sea ice: Synthesis of phenomenon and mechanisms, Antarct. Sci., 16(4), 415-425, doi:10.1017/S0954102004002238.

Yuan, X., and D. G. Martinson (2000), Antarctic sea ice extent variability and its Global Connectivity, J. Clim., 13, 1697-1717, doi:10.1175/1520 0442(2000)013<1697:ASIEVA>2.0.CO;2.

Yuan, X., and D. G. Martinson (2001), The Antarctic Dipole and its Predictability, Geophys. Res. Lett., 28, 3609-3612, doi:10.1029/ 2001 GL012969.

Yuan, X., D. G. Martinson, and W. T. Liu (1999), Effect of air-sea-ice interaction on Southern Ocean subpolar storm distribution, J. Geophys. Res., 104(D2), 1991-2007, doi:10.1029/98JD02719.

C. Li and X. Yuan, Lamont-Doherty Earth Observatory of Columbia University, 61 Route 9W, P.O. Box 1000, Palisades, NY 10964, USA. (xyuan@ldeo.columbia.edu) 